\title{
LA MATRIZ MOVIMIENTISTA DE ACCIÓN COLECTIVA EN ARGENTINA: LA EXPERIENCIA DEL ESPACIO MILITANTE KIRCHNERISTA
}

\author{
The movement matrix of collective action in Argentina: \\ the experience of the kirchnerista militant space
}

\author{
Germán J. PÉREZ y Ana NATALUCCI \\ Instituto de Investigaciones Gino Germani, Universidad de Buenos Aires (Argentina) \\ \ermanjav@yahoo.com.ar \\ $\bowtie$ anatalucci@mail.fsoc.uba.ar
}

BIBLID [1130-2887 (2010) 54, 97-112]

Fecha de recepción: mayo del 2008

Fecha de aceptación y versión final: enero del 2010

RESUMEN: La asunción de Néstor Kirchner fue interpretada por algunas organizaciones sociales y piqueteras como parte de un proceso de reconstitución política. A partir de este hito, redefinieron su estrategia organizacional y de confrontación con el régimen político; se propusieron conformar frentes que pudieran reposicionar a las organizaciones y a sus dirigentes en un proceso de recreación del imaginario movimientista fuertemente enraizado en la cultura política de los sectores populares en Argentina. La propuesta de este artículo es reconstruir el espacio militante kirchnerista emergente en este contexto. Se pretende analizar su proceso de emergencia, tratando de dar cuenta de los vínculos generados entre esas experiencias y la dinámica de la movilización. Finalmente, se propone una evaluación de las virtudes políticas de una matriz movimientista en el horizonte político contemporáneo en Argentina.

Palabras clave: matriz movimientista, kirchnerismo, organizaciones piqueteras, representación política, Argentina.

ABSTRACT: The assumption of Néstor Kirchner was interpreted by some social organizations and piqueteros as part of a process of political reconstruction. From this milestone, they redefined its organizational strategy and confrontation with the political regime; they also proposed forming fronts that could reposition the organizations and their leaders, in a process of re-creation of imaginary movements strongly rooted in the political culture of popular sectors in Argentina. The proposal of this article is to reconstruct the kirchnerista militant space emerging in this context. 
The intention is to analyse the process of emergency, trying to account for the links generated between those experiences and dynamics of mobilization. Finally, there is an assessment of the political virtues of a matrix of mobilization movements in the contemporary political horizon in Argentina.

Keys words: movement matrix, kirchnerismo, piqueteros' organizations, political representation, Argentina.

\section{INTRODUCCIÓN}

Las elecciones presidenciales de mayo de 2003 no fueron una mera instancia estipulada de renovación de autoridades, por el contrario se realizaron: «...en circunstancias anormales y con la expectativa de fijar un rumbo y dar alguna clase de respuesta al profundo cuestionamiento ciudadano de la representación política existente» (Cheresky, 2004: 21). En este sentido, la fórmula Kirchner-Scioli fue parte central del entramado del entonces presidente provisional, Eduardo Duhalde, para evitar que el ex presidente Carlos Menem fuera elegido nuevamente. Asimismo, el triunfo de la fórmula oficial fue un corolario más de la deserción de Menem en el ballotage, que de la expectativa política que logró concitar. En este marco, el flamante presidente asumió con apenas el 22,24\% de los votos. A pesar del escaso apoyo electoral inicial, Kirchner pudo constituir a través de su gobierno un «electorado poselectoral» (Cheresky, 2004: 21).

En su discurso de asunción, Kirchner se expresó a favor de reconstituir el proyecto nacional, subordinar la economía a la política y, por último, remarcó su intención de fortalecer los vínculos con otros países latinoamericanos en una alianza estratégica regional. Al mismo tiempo, apeló a la búsqueda de una estabilidad política que instituyera una nueva normalidad; a partir de esto fundamentó la necesidad de avanzar en el desmantelamiento de la impunidad, que benefició por dos décadas a los responsables de los delitos de lesa humanidad cometidos entre 1976 y 1983, así como la renovación de los miembros de la Corte Suprema de Justicia. También reivindicó la militancia setentista en demérito de la «teoría de los dos demonios», hegemónica desde la década de 1980, que igualaba los crímenes del terrorismo de Estado con las acciones de las organizaciones político-militares. Por último, ubicó al Estado como la entidad capaz de reconstruir ese proyecto nacional. En definitiva, Kirchner reintrodujo ejes en el debate público que generaron la imagen de un gobierno dinámico y con capacidad de interpelación y representación de los sectores populares desde una renovada tradición movimientista, que había significado su principal matriz de integración a la disputa política nacional desde 1945 .

Respecto de la movilización social, la estrategia kirchnerista combinaba la decisión de no reprimir con un discurso que se asentaba sobre la convocatoria a la «normalidad». En la lógica oficial, las organizaciones piqueteras eran un corolario de la fragmentación social, emergente en la década de 1990 y que la crisis de 2001 remató dramáticamente. En consecuencia, en una coyuntura de normalización política, el curso 
de aquéllas debía caracterizarse por la integración y la desmovilización. Bajo esta premisa general, el gobierno tuvo una doble estrategia para el espacio piquetero, que por entonces mantenía una significativa centralidad a pesar de su fractura interna. Por un lado, se produjeron revisiones de la política social implementada durante el gobierno de Duhalde con una amplia convocatoria a la integración a la coalición de gobierno ${ }^{1}$. Por otro lado, aunque no se aplicó una política represiva para las organizaciones que sostenían la estrategia de confrontación, se pusieron en funcionamiento otros desactivadores, como la estigmatización y judicialización de los participantes en las protestas. Esta estrategia se llevó adelante en el contexto de un espacio piquetero ya fragmentado y deslegitimado por los medios de comunicación, en lo que Svampa y Pandolfi (2004) denominaron campaña «antipiquetera» ${ }^{2}$. En este marco, se reabrieron discusiones alrededor de dos aspectos fundamentales de la identidad piquetera: la legitimidad del corte de ruta como repertorio de acción colectiva y la participación de las organizaciones en la distribución y gestión de los planes sociales.

En la dinámica de la movilización se produjeron dos grandes cambios. El primero fue que aquellas organizaciones piqueteras que, según sus tradiciones y marcos interpretativos, adherían al universo nacional y popular, leyeron las declaraciones y los primeros gestos del presidente en la clave de las tres banderas históricas del peronismo: soberanía política, independencia económica y justicia social; también destacaron la convocatoria a la reconstrucción del movimiento nacional. Éste fue el caso, principalmente, del Movimiento de Trabajadores Desocupados Evita (MTD Evita) y de la Federación de Tierra, Vivienda y Hábitat (FTV). Esta última, perteneciente a la Central de los Trabajadores Argentinos (CTA), central alternativa y autónoma fundada a mediados de la década de 1990 y protagonista fundamental de la movilización contra el modelo neoliberal. Para completar el cuadro de las organizaciones que consideraremos, es destacable la posición de Barrios de Pie que interpretó el cambio de coyuntura como

1. Si bien la política social de la gestión de Kirchner mantuvo el criterio de focalización, masividad y centralización a nivel nacional, en agosto de 2003 el Ministerio de Desarrollo Social realizó una reformulación de los planes, que trastocó la lógica del Plan Jefes y Jefas de Hogar Desocupados (caracterizado por una importante distribución). De esta manera, se lanzó el plan de Desarrollo Local y Economía Social (Manos a la Obra y de Emergencia Habitacional), de Seguridad Alimentaria y Familias. La modalidad de implementación del primero fue a través de cooperativas constituidas por las mismas organizaciones. Los autores agradecen los comentarios de los evaluadores anónimos de América Latina Hoy, Revista de Ciencias Sociales.

2. Si el lector revisa los principales periódicos nacionales, Clarín y Nación, desde la asunción de Kirchner hasta finales de 2004 podrá observar que los medios de comunicación participaron de la campaña «antipiquetera». Ésta se constituyó a partir de dos argumentos. Uno, la adscripción partidaria de algunas organizaciones, donde se cuestionaba su representatividad y se le atribuían intereses ajenos a la problemática de los desocupados. El efecto buscado era generar una división entre «buenos»y «malos» piqueteros. El segundo argumento giró en torno al formato de la protesta en términos de vulneración de derechos: el de protestar o circular libremente. Esta estrategia se combinó con la de judicializar las protestas. Respecto de la discusión sobre los derechos y las respuestas del Poder Judicial se recomienda la lectura de R. GARgarella (2006). Sobre los rasgos centrales de dicha campaña, véase M. Svampa y C. PANDOLFi (2004). 
un quiebre en la alianza entre la coalición gobernante y el sector concentrado del capital financiero que había regido durante los últimos treinta años.

A partir de estos diagnósticos, se produjeron algunos desplazamientos tanto en los aspectos identitarios como en el tipo de intervención política. Respecto de los primeros, las organizaciones dejaron de reconocerse y llamarse «piqueteras» para identificarse como sociales ${ }^{3}$, lo cual trajo repercusiones en los alineamientos interorganizacionales y el tipo de alianzas políticas. Acerca de la modalidad de intervención pública, se empezó a priorizar, antes que la realización de protestas callejeras, el trabajo territorial en los barrios y la progresiva incorporación a los planteles de gobierno, como agentes de la administración pública en las áreas correspondientes a sus intereses organizacionales.

Empero, estas transformaciones se produjeron en el marco de un incipiente crecimiento económico que desplazó el problema público -estructurado en torno al eje de la desocupación y las políticas sociales paliativas- hacia la cuestión de la integración al mercado de trabajo, la calidad del empleo y la promoción de la economía social como alternativa de producción. Con mayor razón, el panorama de la movilización social se vio alterado por la recuperación económica como consecuencia de la relativa revitalización del sindicalismo, principalmente a partir de una fuerte reactivación de la negociación colectiva ${ }^{4}$.

En el curso de estas transformaciones emergió un espacio militante, autorreconocido como kirchnerista, en el que los rastros de la experiencia piquetera se combinaron con una redefinición de la relación con el régimen político cifrada en la recreación de una matriz movimientista de participación y movilización.

Tomando como referencias las fuentes primarias generadas por este entramado organizacional, a continuación se propone desplegar el análisis de estas experiencias políticas en tres dimensiones sucesivas: (a) describir la conformación y dinámica organizativa del espacio de organizaciones sociales kirchneristas, favorecida por un diagnóstico común acerca del contexto de oportunidades políticas generado por el nuevo gobierno; (b) analizar las tensiones y conflictos al interior del espacio, tomando como referencia la recreación de los debates propios de la izquierda peronista que se generó entre los principales referentes de esta trama organizativa; (c) evaluar críticamente la productividad política de las gramáticas movimientistas de la acción colectiva atendiendo a la complejidad política de la Argentina contemporánea.

3. Barrios de Pie, incluso para justificar este desplazamiento, construyó una visión de su propia historia diferenciando entre la etapa piquetera y la etapa de institucionalización del reclamo que, a diferencia de la anterior caracterizada por la confrontación y movilización, intentaba la integración a la coalición de gobierno y la participación en la formulación de políticas de Estado.

4. H. Palomino y D. Trajtemberg (2006: 47) sostienen que «durante 2006, en Argentina, fueron homologados 930 convenios y acuerdos colectivos entre sindicatos y empleadores, la cifra más alta de los últimos 15 años. Este auge de la negociación colectiva se inscribe en un ciclo prolongado que desde 2003 no tiene precedentes tanto por la cantidad de negociaciones como por sus contenidos y, en especial, por el contexto singular en el que tiene lugar». 
II. MILITANCIA KIRCHNERISTA, EXPERIENCIAS MOVIMIENTISTAS Y RECONSTRUCCIÓN DEL MOVIMIENTO NACIONAL

Las organizaciones autorreconocidas kirchneristas atravesaron desde mediados de 2003 hasta 2006 un proceso de acercamiento y articulación de estrategias. En principio, el supuesto compartido se restringía a la caracterización de las oportunidades abiertas por el gobierno nacional. Este proceso fue denominado por los propios protagonistas, las organizaciones y el mismo presidente como la «transversalidad». Este espacio, caracterizado como alternativo a la estructura del Partido Justicialista (PJ), abría un doble juego de oportunidades: por un lado, le permitiría a la coalición de gobierno contrarrestar el peso electoral del Partido Justicialista y, por otro, devolvía a las organizaciones el imaginario protagónico en la reconstrucción del movimiento nacional y popular. En definitiva, la expectativa confiada en el proyecto de la «transversalidad» se vinculó con la recomposición del movimiento popular y del proyecto nacional cifrado en la recuperación de una política productiva y la recomposición del mercado interno (documento «Declaración Política del Frente de Organizaciones Populares», septiembre de 2004). La expectativa de concretar estas transformaciones estaba condicionada por el fortalecimiento de la intervención estatal y el liderazgo presidencial en un marco de creciente participación institucional de las organizaciones sociales.

De acuerdo a la caracterización de Godio (2004), en la experiencia «transversal» participaron cuatro afluentes, a saber: (a) corrientes políticas nacionalistas peronistas distanciadas del PJ; (b) un desprendimiento del Frente Grande, integrado por dirigentes que habían abandonado el peronismo a principios de la década de 1990; (c) socialdemócratas y social-liberales con afiliación a la UCR, Partido Socialista (sobre todo funcionarios de la provincia de Santa Fe) y del Partido Intransigente; (d) organizaciones sociales de raigambre peronista, izquierda nacional o socialcristiana, que construyeron agrupaciones de desocupados. A estos cuatro habría que agregar aquellos militantes que decidieron integrarse al espacio.

El «espacio transversal» intentó organizarse de manera tal que pudiera afirmarse como protagonista legítimo en la intervención política. En este sentido, entre mediados y fines de 2004 se constituyeron dos frentes: el Frente de Organizaciones Populares (FOP) y luego el Frente Patria para Todos (FPT).

A principios de junio de 2004, la FTV, el Movimiento Barrios de Pie, el Frente Transversal Nacional y Popular y el MTD Evita convocaron con el documento «La Hora de los Pueblos» a la constitución de un espacio kirchnerista por fuera de la estructura orgánica del PJ ${ }^{5}$. El 21 de ese mismo mes se realizó un encuentro de delegados donde

5. Además de las organizaciones convocantes, adhirieron al documento fundacional: Mov. por la Victoria del Pueblo, MP20, Partido Comunista Congreso Extraordinario, Mesa Kirchner Presidente, Frente de Trabajadores Desocupados Eva Perón, POR Posadista, M26, Agrupación Docente Suteba (Matanza), Grupo de Base 25 de Mayo, Centro de Estudios Hernández Arregui, Comisión Sanitaria Nacional, FAPU Avellaneda, UTD, Agrupación Compromiso, Juventud Presente, Venceremos, Movimiento Político Social (Córdoba), Organización Social Padre Mugica, Movimiento $1^{\circ}$ de Mayo de Trabajadores de Construcción (Misiones), Agrupación Pino Solanas, Grupo Federal Oriente (Frenapo 
se acordaron los principales puntos de acuerdo del FOP. El posicionamiento consensuado respecto del gobierno nacional se sintetizaba en la idea de una «nueva oportunidad histórica que tiene el campo popular, comparable a la que vivimos en los '40»' (documento «Por la recuperación del Trabajo y la Justicia Social. Fuerza Cro. Presidente Néstor Kirchner!!!», junio de 2004). En otras palabras, se conjeturaba que la asunción de Kirchner había producido una ruptura del modelo socioeconómico imperante desde la década de 1970. Tal caracterización también admitía que la integración del gobierno no era homogénea, sino que aún perduraban sectores vinculados al menemismo. Esta lectura operó como fuente de legitimidad para la constitución del frente político: para los organizadores, la etapa de «resistencia» había finalizado y se debía aprovechar la experiencia acumulada y pasar a la fase «ofensiva». En este marco era fundamental «reconstituir el movimiento nacional a fin de afianzar la unidad de concepto y acción entre el gobierno y las fuerzas populares» (documento Diez puntos para la unidad de las fuerzas populares, diciembre de 2004).

A propósito de un nuevo aniversario de la muerte de Eva Perón, el Frente de Organizaciones Populares preparó un acto para presentarse oficialmente y convocar a otras organizaciones a integrarse y apoyar la gestión de Kirchner. En el documento «Por la recuperación del Trabajo y la Justicia Social. Fuerza Cro. Presidente Néstor Kirchner!!!» (2004), el Frente declaró lo siguiente:

Desde el Frente Nacional de Organizaciones Populares hemos decidido asumir a pleno nuestra responsabilidad social y política en esta hora y colocar nuestros esfuerzos en sintonía con los del Presidente de la Nación [...] Estamos empeñados en la construcción de más y mejor organización social y política, como contribución esencial a la recomposición y unidad del campo popular. Lo hacemos con la misma pasión y entrega que nos enseñara Evita. Consustanciados de su fervor revolucionario y su amor al pueblo. A favor de la vida y de la justicia, del reconocimiento efectivo que donde hay una necesidad, hay un derecho (Frente Nacional de Organizaciones Populares, julio de 2004).

Para septiembre la FTV, el MTD Evita, Barrios de Pie y el Frente Transversal habían conformado la Mesa Coordinadora por un Nuevo Proyecto Nacional, a partir de la cual

Capital), Red de Mujeres Solidarias, 22 de Agosto, Frente Peronista Nuevo Sur, Juana Azurduy (Mendoza y Capital), Asamblea Pompeya, Gráficos Córdoba, Sin Fronteras, Mov. Peronista de Escobar, Frente Social Ramón Carrillo, Frente Social de Avellaneda, Agrup. Eva Perón, Mutual Sol, Mutual Sentimiento, Docentes de Lomas de Zamora, Cros. de ATC, Tesis 11, Causa Popular, Cros. de la Verde, Memoria y Movilización, Confluencia Río Negro, Red Martín Fierro, Moveos, Grupo Bases Peronistas, UTD Rosario, Partido Nuevo (Córdoba), Movimiento $1^{\circ}$ de Mayo, Red Social y Cultural, Coordinadora Mataderos, Agrup. Gral. San Martín, Patria Morena, Soc. Fomento Solano, Asamblea Gral. Corrales, Patria Libre, 4P, Encuentro Social de Tucumán, Coordinadora Agustín Tosco, La Pampillón y Movimiento Octubres. Con el correr de los meses algunas organizaciones dejaron el espacio. FTV, Barrios de Pie, MTD Evita y el Frente Transversal siguieron siendo los principales convocantes (consultado el 27 de julio de 2006. Disponible en: http://www.ftv.org.ar/documentosftv.htm).

6. La remisión a la década de 1940 aludía a la etapa del peronismo clásico, de profundos cambios políticos y económicos. 
convocaron a un nuevo encuentro. A la Mesa se incorporaron Miguel Bonasso (Partido de la Revolución Democrática), Eduardo Luis Duhalde (Memoria y Movilización Social, secretario de Derechos Humanos de la Nación) y Francisco «Barba» Gutiérrez (Polo Social). La mayoría de los dirigentes de la Mesa habían tenido una militancia en la izquierda peronista. El acto se realizó el 12 octubre de 2004 en el estadio porteño Luna Park con la consigna «Junto al Presidente Néstor Kirchner por una Patria para todos». Allí participaron también el ministro de Trabajo, Carlos Tomada, la ministra de Desarrollo Social, Alicia Kirchner, y el secretario general de la Presidencia, Óscar Parrilli. La presencia de funcionarios nacionales vinculados directamente a Kirchner se repetiría en las siguientes experiencias. El acto fue una excelente oportunidad para «impulsar una nueva coalición política que contribuya a sostener y profundizar la acción gubernamental» (documento Juntos al Presidente Néstor Kirchner por una Patria para todos, octubre de 2004).

Entre finales de octubre y diciembre, el espacio se dedicó a establecer acuerdos con otras organizaciones, principalmente con CTA, y también con ciertos funcionarios de origen no peronista, como los intendentes de la Ciudad de Buenos Aires (Aníbal Ibarra), Rosario (Hermes Binner) y Córdoba (Luis Juez). Este nuevo espacio se denominó Frente Patria para Todos. El congreso fundacional se realizó el 12 de diciembre de 2004. Los organizadores calcularon la participación de dos mil delegados de todo el país. Los temas de discusión giraron en torno a la apertura de condiciones luego de la asunción de Kirchner y las posibilidades de integración en la gestión de gobierno. La meta de este encuentro fue iniciar un proceso de consolidación de una fuerza política en vistas a las elecciones legislativas de 2005. Como resultado de las comisiones de trabajo se elaboró el documento Diez puntos para la unidad de las fuerzas populares, donde se asentaron los acuerdos programáticos del espacio ${ }^{7}$. En pocas palabras, la convocatoria del Frente podría sintetizarse en el siguiente fragmento:

7. El documento Diez puntos para la unidad de las fuerzas populares sintetizaba los siguientes acuerdos: 1) Alcanzar una justa distribución del ingreso, con inclusión social, trabajo y salario digno para todos los argentinos; 2) Subordinar el abordaje y resolución del problema de la deuda externa a nuestro desarrollo económico con justicia social;3) La reconstrucción de nuestra industria nacional, con desarrollo de la ciencia y la tecnología y la recuperación del talento emigrado; 4) Escuela, techo y salud para todos los habitantes de nuestra patria; 5) El impulso a nuevas políticas sociales que privilegien la protección de los derechos de los niños y la ancianidad, y contribuyan a fortalecer la organización popular; 6) La recuperación del papel estratégico del Estado, la defensa de nuestros recursos naturales y el afianzamiento de nuestra soberanía nacional; 7) Una alianza de las naciones sudamericanas, como paso decisivo hacia la integración total de América Latina; 8) La defensa y promoción de nuestra cultura nacional; 9) La profundización de la democracia con nuevas formas de representación y participación popular y 10) La recuperación de la memoria histórica, la vigencia integral de los derechos humanos, el impulso de la equidad de género y el respeto a los pueblos originarios. Firmaron el Documento los dirigentes en nombre de sus organizaciones: Bonasso (PRD), D'Elía (FTV), E. L. Duhalde (Memoria y Movilización), Ceballos (Barrios de Pie), Depetri (Frente Transversal), Gutiérrez (Polo Social), Emilio Pérsico (mTD Evita), Girotti (MPV), Jorge Pereyra (Partido Comunista CE), Lito Rossi (POR Posadista), Mary Sánchez (Mov. Social y Solidario), Rodolfo Casals (Corriente Social Bonaerense), Marcelo Jaket (Mov. 26 de Julio), Gastón Harispe (Octubres). 
...cerrar filas en torno al ideario de la justicia social, el desarrollo económico y la democracia participativa. La conformación de un gran frente social y político capaz de representar y canalizar el protagonismo de las mayorías populares, que recupere para el pueblo las instituciones de la República, acabe con la impunidad y la corrupción y nos permita construir un país más justo y solidario, por el que soñaron y dieron su vida los treinta mil desaparecidos y tantos otros luchadores populares que nos precedieron (documento Diez puntos para la unidad de las fuerzas populares, diciembre de 2004).

De esta forma, el espacio transversal inscribía la movilización kirchnerista en un relato que reunía las luchas populares de las décadas de 1940, 1970 y 1990 como expresión de un mismo conjunto de demandas y un sujeto político que reaparece en los momentos críticos de la historia nacional. En esta nueva etapa, el Frente se proponía «llenar el vacío de representatividad dejado por la crisis de los viejos partidos» (Declaración de la Mesa Coordinadora para un Nuevo Proyecto Nacional, junio de 2004).

A partir de este relato es pertinente señalar una ruptura en la dinámica de la movilización social. En otras palabras, además de cambios en el marco de confrontación, los movimientos filokirchneristas se reposicionaron como los herederos de un proceso mayor, cuya tarea actual era no sólo organizar a los sectores populares, sino constituirse en su representación política. En este marco, la movilización se desplazó de la ruta a la plaza simbolizando el retorno de las organizaciones sociales a una proximidad inmediata con el centro del poder, referencia excluyente del cambio social en la extensa tradición movimientista nacional.

\section{PERONISMO Y TRANSVERSALIDAD: LAS DISCUSIONES DE LA IZQUIERDA PERONISTA EN TORNO A LA MODALIDAD DE CONSTRUCCIÓN POLÍTICA}

La construcción de la «transversalidad» tuvo alcance limitado por la concurrencia de varios factores. Por un lado, más allá de la reivindicación nacional y popular, las diferencias ideológicas y de tradición política entre las organizaciones participantes eran importantes. Algunas tenían una trayectoria en la Democracia Cristiana, otras en la izquierda nacional, en organizaciones independientes y también en el peronismo. No obstante, el punto divisorio se asentaba sobre la apropiación de la identidad peronista. Si bien ésta era reivindicada, no todas estaban convencidas de construir su interpelación pública a partir de aquélla, sobre todo por la constante referencia a Evita y la etapa mítica del peronismo (1945-1955). Por otro lado, sus acciones se limitaron a la difusión de documentos de tinte más reclamativo que propositivo; posiblemente esto se haya relacionado con que los márgenes de acuerdo respecto de las estrategias de intervención eran más bien difusos.

Otra cuestión relativa a esta diversidad era la desigualdad en la capacidad de movilización de recursos entre las organizaciones convocantes; es decir, mientras algunas, como la FTV o Barrios de Pie, tenían una significativa capacidad de movilización y una 
extendida construcción territorial, otras estaban conformadas por grupos de militantes o funcionarios, tal como el PRD o Memoria y Movilización de M. Bonasso y E. L. Duhalde respectivamente. Probablemente, este contraste haya aparejado algunas disputas personales, en detrimento de la consolidación del Frente. Por último, su objetivo de constituirse en una coalición política que disputara con el PJ la hegemonía en el espacio kirchnerista era complejo y confrontaba con el armado electoral del propio Kirchner, quien no desdeñaba la participación de dirigentes tradicionales del Partido Justicialista en los niveles subnacionales.

La diferencia fundamental se asentaba sobre las distintas modalidades de construcción política que repusieron una discusión que en la década de 1970 se articuló alrededor de tres opciones: movimientismo, tendencia o alternativa independiente. A riesgo de omitir algunos matices, se considera que estas alternativas tienen una importante productividad analítica en tanto permiten comprender las tensiones al interior de este espacio político.

Si bien esas tres opciones estaban incorporadas al lenguaje militante, Lanusse (2005) las propuso como tipología para comprender las disputas y discusiones dentro del peronismo de la década de 1970 y la posición concedida al «enemigo»:

Con el tiempo, se fueron perfilando dos posturas que serían conocidas como «movimientismo» por un lado, y «alternativa independiente» por el otro. Equidistante de ambas se ubicaba la idea de conformar una «tendencia revolucionaria» dentro del Movimiento. [...] Los movimientistas creían en un peronismo revolucionario en su conjunto, y en un Perón también revolucionario. Por lo tanto, relegaban a un segundo plano las diferencias dentro del Movimiento. No desconocían la existencia de «traidores», pero creían que la propia dinámica de la lucha los obligaría a sumarse a la misma o quedar a un lado. Los tendencistas sostenían que dentro del Movimiento Peronista existían diferencias irreconciliables en cuanto a los objetivos estratégicos, pero le reconocían al mismo tiempo su potencialidad revolucionaria y llamaban a dar el combate en su interior. Esta posición asumía que si Perón no era genuinamente revolucionario, por lo menos estaba dispuesto a volcarse en ese sentido. En esta visión, los «burócratas» eran enemigos, pero se toleraba la convivencia «táctica» con ellos. Los alternativistas mantenían la identidad peronista, pero descartaban cualquier tipo de convivencia con los «burócratas». Pensaban que la historia del Movimiento demostraba que las burocracias, a través de sus estructuras, terminaban imponiéndose y aplastando los objetivos revolucionarios. El alternativismo era, en definitiva, una postura clasista: proponía que la clase obrera desarrollara una herramienta política propia, independiente de «burócratas» $\mathrm{y}$ «traidores» (Lanusse, 2005: 255-256).

Si se leyeran esas opciones en torno a las experiencias kirchneristas se podría establecer el siguiente ordenamiento. El MTD Evita en la opción «movimientista», en sus palabras:

...la posición movimientista [apela a la] reconstrucción del movimiento nacional encarnado en la conducción de Kirchner y también cuando decimos que nuestro destino está 
intrínsecamente vinculado al destino de nuestro Presidente. El movimientismo coloca a la contradicción principal fuera del kirchnerismo... (Koenig, 2006: 19).

El MTD se propuso construir un movimiento que nucleara las experiencias que aspiraban a intervenir en el régimen bajo la entidad kirchnerista. Asimismo, pretendía mejorar su posicionamiento en el Frente para la Victoria, espacio político y coalición electoral donde intervenía el PJ y usufructuar el cupo destinado a las organizaciones sociales. El corolario de estos propósitos fue la constitución del Movimiento Evita.

La posición que remedaba a la «tendencia» reconocía las oportunidades favorables del proceso abierto a posteriori de la asunción de Kirchner, pero tenía serias dudas de confluir en el Frente para la Victoria. En términos de aquella trilogía, esta opción alude a un gobierno en disputa y en consecuencia su apoyo está condicionado por otros factores coyunturales. A esta posición adhirió Barrios de Pie:

Nosotros creemos que dentro de lo que es el kirchnerismo hay básicamente dos espacios bien delimitados: el kirchnerismo dentro del PJ y el kirchnerismo por fuera del PJ. Dentro del kirchnerismo por fuera del PJ es el andarivel por donde nosotros queremos construir un movimiento político que profundice las medidas que este gobierno ha esbozado a partir del presidente (entrevista a dirigente provincial de Córdoba de Libres del Sur, febrero de 2006).

Barrios de Pie, organización piquetera creada por la Corriente Nacional Patria Libre, proponía la constitución de un frente que participara de los comicios y mantuviera, al mismo tiempo, cierta autonomía que evitara subsumir su proyecto al PJ. En este marco, definió la conformación del Movimiento Libres del Sur como herramienta electoral.

La última posición, la «alternativa independiente», que en el imaginario peronista remitía a la experiencia del Peronismo de Base (PB) y de las Fuerzas Armadas Peronistas (FAP), fue tomada principalmente por la CTA y profundizada en su $7 .{ }^{\circ}$ Congreso, cuando su secretario general afirmó que: «... esta Central tiene claro que jamás estará subordinada a un partido, una empresa o a un gobierno...» (De Gennaro, 2006). De esta manera, la CTA se ubicó por fuera de cualquier participación posible dentro del espacio kirchnerista. La posición de «Central obrera alternativa y autónoma de partidos y empresarios» que era una bandera histórica de la CTA -fundamental en su estrategia de resistencia al menemismo- comenzó a mostrar sus limitaciones para el tránsito a una etapa más ofensiva de la lucha. A partir de 2002, con el lanzamiento del Movimiento Político y Social en el 6. ${ }^{\circ}$ Congreso de Delegados, las estrategias de construcción política que proyectaban a la Central como el nucleamiento sindical del cual resultaría un Partido de los Trabajadores al modelo brasileño, comenzaron a evidenciar marcadas dificultades que se reflejaron en la retracción del protagonismo de la CTA durante los años subsiguientes.

Tales dificultades pueden resumirse en dos cuestiones fundamentales: por un lado, los problemas de la Central para ampliar sus bases de representación de intereses más allá de los gremios estatales, agravada por la persistente denegación del reconocimiento 
jurídico de su personería gremial; por el otro, el marcado protagonismo que adquiere su principal organización de base territorial -la FTV- que con el advenimiento del kirchnerismo asume una posición de alineamiento con el gobierno contraria a la estrategia alternativa de la Central. Ambos dilemas obstaculizaron la conformación de un dispositivo de interpelación y liderazgo político que permitiera a la Central cumplir con su expectativa de pasar de las luchas reivindicativas a las estrategias de construcción/acumulación política. Esas tensiones se plasmaron en confusas estrategias electorales, en las cuales la unidad política de la organización quedaba diluida en la participación de sus principales referentes en fuerzas políticas con propuestas y procedencias ideológicas contradictorias.

Consecuentemente, el «espacio transversal» tuvo una trayectoria acotada; su proceso aparejó varios correlatos que trastocaron la dinámica de la movilización. Dos aspectos sobresalen. El primero está relacionado con que la experiencia del Frente propició el acercamiento entre organizaciones con afinidades en términos de tradiciones e identidades que favorecieron la constitución de otros dos: el Movimiento Evita en mayo de $2005^{8}$ y el Movimiento Libres del Sur en abril de $2006^{\circ}$. Una de las diferencias entre ambas experiencias se observa en el nombre. Para el Movimiento Evita, la incorporación de la figura de Eva Perón fue un intento por recuperar la tradición más disruptiva y plebeya del peronismo ${ }^{10}$. Esta operación de sentido fue complementada con el tipo de iconografía utilizada que inscribía al Movimiento en la tradición radicalizada del peronismo, vinculada a las organizaciones político-militares de la década de 1970.

Para el Movimiento Libres del Sur, el nombre reivindicaba las diferentes experiencias latinoamericanas y apelaba a la capacidad de la autodeterminación de las naciones del sur. La denominación expresaba el propósito de las organizaciones de fortalecer los lazos con los países de la región, especialmente con el proceso venezolano con el cual tenían

8. El acto de lanzamiento fue el 10 de mayo de 2005 en el Luna Park, allí participaron funcionarios nacionales y las organizaciones que confluyeron en el Evita: MTD Evita, MTD Resistir y Vencer, Movimiento Patriótico 20 de Diciembre, agrupación Martín Fierro/FB19, Frente Transversal Nacional y Popular, Movimiento Peronista Auténtico, Octubres, la Corriente Sanitaria Federal, Partido Proyecto Popular (Capital Federal, ya integrante del Frente para la Victoria), Movimiento Norte Grande (La Rioja), el Frente de Todos (Corrientes), Unión por Neuquén (UNE) y Patria, Pan y Poder al Pueblo de la localidad de La Plata (4P). Para profundizar sobre el origen y trayectoria del Movimiento Evita véase A. NATALUCCI (2008).

9. El 27 de abril de 2006 se realizó el lanzamiento nacional del Movimiento Libres del Sur, en el Centro Costa Salguero de la Ciudad de Buenos Aires en el «Encuentro por la Patria Grande». Entre las organizaciones participantes se encontraron: el Movimiento Barrios de Pie, el Partido Comunista Congreso Extraordinario, la Agrupación Martín Fierro, el Frente Barrial 19 de Diciembre, la Agrupación Envar el Kadri y la Corriente Patria Libre. Para una reconstrucción de la experiencia de Libres del Sur y la relación con Patria Libre y Barrios de Pie véase A. NATALuCci (en prensa).

10. D. JAMES (1990: 37), refiriéndose a la credibilidad política del peronismo, afirmó que «la atracción política del peronismo era esencialmente plebeya; ignoraba la necesidad de una elite política particularmente iluminada y reflejaba e inculcaba un profundo antiintelectualismo. La glorificación de estilos de vida y hábitos populares involucró un estilo y un idioma político bien a tono con las sensibilidades populares». 
vínculos previos por haber participado en los sucesivos Foros Mundiales realizados en la ciudad de Porto Alegre en Brasil. Pero, como ya se ha mencionado, la principal diferencia radicó en la concepción de construcción política y qué tipo de relación mantener con el peronismo. La disyuntiva oscilaba entre si reivindicarlo en términos de tradición política que aún infunde una mística militante, o bien, como un dispositivo de interpelación ideológica capaz de estructurar una estrategia política en el presente.

El segundo aspecto que sobresale es que, pese a estas diferencias, se mantuvieron algunos acuerdos, en especial el señalamiento de los grupos económicos como el adversario al kirchnerismo sobre el escenario privilegiado de la confrontación.

En consecuencia, si la coyuntura generó nuevas oportunidades que a su vez provocaron un desplazamiento en la entidad considerada antagonista: ¿qué lugar le quedaba a la movilización? Y ¿cuál era el escenario privilegiado para la disputa y construcción política? Aunque ya se ha mencionado, vale remarcar que esa movilización ya no era de confrontación en el sentido de que no estaba atravesada por un conflicto político ${ }^{11}$; no era el Estado el destinatario de las demandas. En estos términos, si la movilización era de apoyo y no de confrontación, en consecuencia, el escenario privilegiado debía ser la Plaza de Mayo.

Ese desplazamiento se manifestó claramente en el tercer aniversario del gobierno de Kirchner. A modo de celebración, el Frente para la Victoria organizó un acto en la Plaza de Mayo bajo la consigna «"Hoy el pueblo sabe de qué se trata". Festejemos juntos el día de la Patria». La convocatoria fue amplia, desde intendentes de la UCR hasta las organizaciones sociales-piqueteras y los sindicatos. Los organizadores calcularon que la concentración fue de 350.000 personas ${ }^{12}$. En su discurso, Kirchner revalorizó la plaza:

Y al final un día volvimos a la gloriosa Plaza de Mayo a hacer presente al pueblo argentino en toda su diversidad. Hace 33 años yo estaba allí abajo, como hoy, creyendo y jugándome por mis convicciones que un nuevo país comenzaba. [...] Como yo siempre dije: no veníamos a la plaza, como decían algunos, que a veces por escribir escriben cualquier cosa, a ocupar un balcón que ya tiene dueño histórico y que nosotros lo seguimos respetando con todas nuestras fuerzas: allí estaban Perón y Eva Perón. [...] Venimos a esta plaza que es de los trabajadores, que es de Eva Perón y que es de las Madres y Abuelas de Plaza de Mayo, a juntarnos los argentinos a celebrar el día patrio (en La Nación, 26 de mayo de 2006) ${ }^{13}$.

11. «El conflicto político incluye todas las ocasiones: 1) en las que algún grupo de personas realiza reivindicaciones colectivas públicas visibles sobre otros actores (reivindicaciones que si se cumplieran afectarían los intereses de estos últimos) y 2) en las que al menos una de las partes afectadas por reivindicaciones, incluyendo terceras partes, es un gobierno». Ver C. TILLY (1998: 30).

12. Clarín calculó 150.000 participantes. Consultado el 27 de julio de 2008. Disponible en: http: //www.clarin.com/diario/2006/05/26/elpais/p-00315.htm.

13. Consultado el 27 de julio de 2008. Disponible en: http://www.lanacion.com.ar/archivo/Nota. asp?nota_id=809122. 
De esta forma el líder recupera la tradición a través de un distanciamiento respecto del significado histórico del balcón, pero restituyendo la legitimidad de los habitantes de la plaza que conforman los pilares colectivos de su construcción política: los trabajadores, los organismos de derechos humanos y el peronismo histórico.

\section{REFLEXIONES FINALES ACERCA DE LA PRODUCTIVIDAD POLÍTICA DE LA MATRIZ MOVIMIENTISTA}

Hasta aquí se ha cumplido con el propósito de describir la evolución y los debates de las organizaciones sociales que han formado parte del espacio kirchnerista. A modo de conclusión interesa proponer algunas reflexiones acerca de la pertinencia de una matriz movimientista de construcción política, a la luz de las transformaciones del régimen político y de los sectores populares en los últimos años.

Una de las características centrales del éxito de esta matriz en Argentina y buena parte de Latinoamérica fue la posibilidad que brindaba de operar la transición entre demandas sociales y su articulación política suprimiendo la intervención del sistema de partidos -la «partidocracia» en la retórica peronista- que se presentaba como una instancia institucional burocrático-formal, capturada por intereses sectoriales y sin perspectivas programáticas. Se ha visto que las organizaciones filokirchneristas compartían esta noción básica de la gramática movimientista. Esta suerte de contigüidad entre la movilización social y su expresión político-estatal en el modelo movimientista clásico se sustentó sobre una clase obrera relativamente homogénea, donde su integración al Estado se realizó mediante estructuras institucionales verticalizadas y con gran capacidad de negociación. En la jerga peronista se trataba de los sindicatos como la «columna vertebral» del movimiento.

El impacto de las políticas neoliberales sobre los sectores populares, sin perjuicio de las profundas transformaciones que experimenta actualmente el trabajo por la expansión de modelos posfordistas de producción, ha complejizado las realidades populares transformando sus modos de acceso a la política. En este sentido, la transición entre lo social y lo político, entre la movilización de demandas y la articulación de un sujeto de acción colectiva con capacidad de intervención en el régimen político, resulta más problemática en la medida que no parece poder realizarse de manera inmediata.

Asimismo, la prioridad asignada por estas organizaciones al Estado como instancia primordial de la intervención política revela la tensión de lo nacional-popular entre una concepción pluralista y otra organicista de la hegemonía (Portantiero y De Ipola, 1989). A idéntica distancia de una matriz política liberal democrática, como de una revolucionaria, el movimientismo de matriz nacional-popular alcanza su realización en la reintegración del pueblo en el Estado, consumando el imaginario de la reconciliación de los diversos intereses privados y sectoriales en un gobierno del pueblo. Sólo el Estado puede recomponer la fragmentación disolvente que amenaza al pueblo real en la forma del individualismo competitivo o la lucha de clases. 
De esta forma, la distorsión que inscribe la interpelación populista en el cuerpo social, articulando las demandas populares en oposición al bloque hegemónico encarnado en el «modelo neoliberal», se reabsorbe en la utopía de un nuevo Estado que ofrece la garantía de la restitución de la ciudadanía social mientras asegura la unidad comunitaria del pueblo en su representación más organicista. Como se constata a lo largo de la rica tradición movimientista nacional, las pulsiones democráticas y organicistas atraviesan el complejo entramado ideológico de las organizaciones analizadas. Representan intereses populares en la lucha por la equidad constitutiva de la ciudadanía social, por un lado, y mantienen una representación orgánica e integrada de la comunidad a distancia de las fuerzas disolventes de la partidocracia liberal y la confrontación clasista, por el otro.

En este sentido, y aunque no formen parte del análisis de este artículo, cabe mencionar la impronta de las gramáticas clasista y autonomista en muchas de las organizaciones que participaron del espacio de resistencia a las consecuencias del modelo de modernización excluyente en Argentina en el segundo lustro de la década de 1990.

Por todo lo expuesto, no parece adecuado enfrentar al modelo delegativo, personalista y de baja institucionalización, propio de 1990 (O'Donnell, 2004) con la tradicional estrategia movimientista. Ambos modelos se muestran refractarios a la principal característica que se entiende que tuvo el ciclo de movilización iniciado en el segundo lustro de la década de 1990 con su dramático corolario en diciembre de 2001: su inerradicable pluralidad. Acaso el ciclo de movilización social que ha experimentado Argentina en las últimas décadas muestre tanto la imposibilidad de restaurar la unidad del pueblo en su verdad prepolítica, como la necesidad de recuperarlo en su dimensión política: la de una comunidad de experiencias y expectativas a ser construida sin suprimir la singularidad de sus voces.

Al calor de este proceso de movilización, se han configurado nuevas formas asociativas de matriz territorial que contribuyeron a una renovación de los lenguajes políticos en lo que respecta a cuestiones claves del régimen político de gobierno. Algunas de esas experiencias son: la autoorganización comunitaria y la autogestión obrera como formas de enfocar las transformaciones del trabajo en el capitalismo postfordista; la dinámica asamblearia como cuestionamiento a las formas delegativas del vínculo político -clientelares y/o patrimonialistas- apuntando a un proceso de conformación autónomo de la voluntad política; la difusión de un lenguaje de derechos que indique la exterioridad irreductible entre justicia y poder político con el propósito de ensanchar los márgenes de un espacio público democrático; y, como corolario, un despliegue pluralista del sujeto popular que promueva la multiplicación y articulación de las luchas, más que su fusión e integración corporativa al aparato del Estado.

Las nuevas gramáticas políticas resultantes no están ajenas al juego de la representación ni al desafío de pensar y producir una renovada institucionalidad democrática. Se considera que la representación política sigue configurando el dispositivo a través del cual los sujetos políticos son interpelados y proyectados en el intervalo entre las identidades definidas por la estructura social o la superestructura jurídica, produciendo el efecto que Jacques Rancière (2006) denomina «suplementación política»: la subversión 
de la imagen de la comunidad como aritmética cerrada de las partes y las funciones. Ahora bien, esta distorsión resulta políticamente productiva si es capaz de conformar un espacio público de expresión y reconocimiento que no quede capturado ni en el aparato del Estado ni en la regulación automática del mercado.

La reedición de una estrategia movimientista, deudora de una concepción organicista y estatalista de la hegemonía, no contribuye, se estima, a la urgente desconcentración funcional y territorial del poder político, indispensable para una institucionalización productiva de estas promisorias, aunque incipientes, formas de la política.

\section{Bibliografía}

Altamirano, Carlos. Peronismo y cultura de izquierda. Buenos Aires: Temas Grupo Editorial, 2001. ARMELINO, Martín. Resistencia sin integración: protesta, propuesta y movimiento en la acción colectiva sindical de los noventa. El caso de la CTA. En NAISHTAT, Francisco et al. Tomar la palabra: nuevos sujetos de acción colectiva en la Argentina. Buenos Aires: Prometeo, 2004, pp. 275-311.

Bossio, Lucas. Entrevista realizada por los autores. Córdoba: 21 de febrero de 2006.

CHERESKY, Isidoro. Elecciones fuera de lo común. Las presidenciales y legislativas nacionales del año 2003. En Cheresky, Isidoro y BLANQuer, Jean-Michel. ¿Qué cambió en la politica argentina? Elecciones, instituciones y ciudadanía en perspectiva comparada. Rosario: Homo Sapiens, 2004, pp. 21-54.

De Gennaro, Víctor. Discurso de Apertura del XII Congreso Nacional de la Central de Trabajadores Argentinos. Buenos Aires: CTA, marzo de 2006.

DE IPOLA, Emilio. Ideología y discurso populista. México: Plaza \& Janés, 1987.

FARINETTI, Marina. ¿Qué queda del «movimiento obrero»? Las formas del reclamo laboral en la nueva democracia argentina. IIGG-FCS-UBA. Buenos Aires: Mimeo, 1999.

Frente de Organizaciones Populares. Documento Presidente Néstor Kirchner!!!, junio de 2004.

Frente de Organizaciones Populares. La Hora de los Pueblos, julio de 2004.

Frente Patria PARA Todos. Juntos al Presidente Néstor Kirchner por una Patria para todos, octubre de 2004.

Frente Patria para Todos. Diez puntos para la unidad de las fuerzas populares, diciembre de 2004.

GARGARELla, Roberto. Carta abierta sobre la intolerancia. Apuntes sobre derecho y protesta. Buenos Aires: Siglo XXI Editores, 2006.

GEPSAC. Transformaciones de la protesta social en Argentina (1989-2003). Buenos Aires: IIGG-FCSUBA, Documento de Trabajo n. ${ }^{\circ}$ 48, 2006.

Godio, Julio. Características y futuro de la Mesa Coordinadora (transversal) de apoyo a Kirchner. Buenos Aires: Rebanadas de Realidad, 2004. Disponible en: http://www.rebanadasderealidad.com.ar/godio-21.htm. Consultado el 29 de julio de 2008.

GRÜNER, Eduardo. La cosa política o el acecho de lo Real. Buenos Aires: Paidós, 2005.

JAMES, Daniel. Resistencia e integración. El peronismo y la clase trabajadora argentina 1946-1976. Buenos Aires: Sudamericana, 1990.

Koenig, Marcelo. ¿Movimiento? era... ¿Movimientismo, Tendencia Revolucionaria o Alternativa Independiente? Revista Evita, 2006, n. ${ }^{\circ}$ 6: 19.

Laclau, Ernesto. Política e ideología en la teoría marxista. México: Siglo XXI, 1980. 
LAnusse, Lucas. Montoneros. El Mito de sus 12 fundadores. Buenos Aires: Vergara, 2005.

LEFORT, Claude. La invención democrática. Buenos Aires: Nueva Visión, 1990.

MANIN, Bernard. La democracia de los modernos. Los principios del gobierno representativo. Revista Sociedad, 1995, n. ${ }^{\circ}$ 6: 13-38.

MARTUCCELli, Danilo y SvAmPA, Maristella. La plaza vacía. Las transformaciones del peronismo. Buenos Aires: Losada, 1997.

Merklen, Denis. Pobres ciudadanos. Las clases populares en la era democrática (Argentina, 19832003). Buenos Aires: Gorla, 2005.

Mesa Coordinadora para un nuevo Proyecto Nacional. Declaración. Buenos Aires: Mesa Coordinadora para un Nuevo Proyecto Nacional, septiembre de 2004.

NatalucCi, Ana. De los barrios a la plaza. Desplazamientos en la trayectoria del Movimiento Evita. En Pereyra, Sebastián. La buella piquetera. Avatares de las organizaciones piqueteras pos crisis de 2001. La Plata: Al Margen, 2008, pp. 117-140.

NATALUCCI, Ana. Aportes para la discusión sobre la autonomía o heteronomía de las organizaciones sociales. La experiencia del Movimiento de Barrios de Pie, 2002-2008. Revista Laboratorio, en prensa, n. ${ }^{\circ} 23$.

O’Donnell, Guillermo. ¿Democracia delegativa? En O'Donnell, Guillermo. Contrapuntos. Ensayos escogidos sobre autoritarismo y democratización. Buenos Aires: Paidós, 2004, pp. 287-304.

Palomino, Héctor y Trajtemberg, David. Una nueva dinámica de las relaciones laborales y la negociación colectiva en Argentina. Revista de Trabajo, 2006, n. ${ }^{\circ}$ 3: 47-68.

PEREYRA, Sebastián; PÉREZ, Germán J. y SCHuster, Federico (eds.). La buella piquetera. Avatares de las organizaciones de desocupados post crisis de 2001. La Plata: Ediciones El Margen, 2008.

PÉREZ, Germán. Pálido fuego: Hannah Arendt y la declinación de la figura del trabajador en las sociedades contemporáneas. Apuntes sobre los piqueteros en Argentina. En NAIsHTAT, Francisco et al. (comps.). Tomar la palabra: nuevos sujetos de acción colectiva en la Argentina. Buenos Aires: Prometeo, 2005, pp. 313-341.

Portantiero, Juan Carlos y De Ipola, Emilio. Lo nacional-popular y los populismos realmente existentes. En De IpOLA, Emilio. Investigaciones políticas. Buenos Aires: Nueva Visión, 1989, pp. 21-36.

RANCIÈRE, Jacques. El odio a la democracia. Buenos Aires: Amorrortu, 2006.

SvAMPA, Maristella y PANDOLFI, Claudio. Las vias de la criminalización de la protesta en Argentina, 2004. Disponible en http://www.maristellasvampa.net/archivos/ensayo16.pdf. Consultado el 21 de julio de 2008.

Tilly, Charles. Conflicto político y cambio social. En IBARRA, Pedro y Tejerina, Benjamín. Los movimientos sociales. Transformaciones políticas y cambio cultural. Madrid: Trotta, 1998, pp. 25-41.

VIRno, Paolo. Gramática de la multitud. Para un análisis de las formas de vida contemporáneas. Buenos Aires: Colihue, 2003. 